\title{
Estabelecimento de Pyrenophora chaetomioides em Cariopses de Aveia Branca em Condições de Campo*
}

\author{
Carlos R. E. da Rosa ${ }^{* * 1}$, José A. Martinelli**1, Luiz C. Federizzi**2 \& Carla A. C. Bocchese ${ }^{1}$ \\ ${ }^{1}$ Departamento de Fitossanidade, ${ }^{2}$ Departamento de Plantas de Lavoura, Faculdade de Agronomia, Universidade Federal do \\ Rio Grande do Sul, Cx. Postal 776, CEP 91540-000, Porto Alegre, RS, fax: (051) 3316-6015, e-mail: jamfito@ ufrgs.br
}

(Aceito para publicação em 16/04/2003)

Autor para correspondência: José A. Martinelli

ROSA, C.R.E., MARTINELLI, J.A., FEDERIZZI, L.C. \& BOCCHESE, C.A.C. Estabelecimento de Pyrenophora chaetomioides em cariopses de Avena sativa em condições de campo. Fitopatologia Brasileira 28:442-445. 2003.

\begin{abstract}
RESUMO
A mancha foliar e do grão da aveia (Avena sativa), denominada "helmintosporiose da aveia", causada pelo fungo Pyrenophora chaetomioides é uma doença de importância para o Brasil. Com o objetivo de identificar em que fase do desenvolvimento as cariopses de aveia branca apresentam-se mais suscetíveis à infecção por $P$. chaetomioides, foram conduzidos três experimentos de campo. Panículas de plantas de aveia foram expostas ao inóculo por períodos determinados de tempo desde a sua emergência. Através da utilização de sacos confeccionados com papel celofane, foram aplicados tratamentos que consistiam na proteção ou na exposição das panículas durante o desenvolvimento das cariopses. No final do ciclo, as

panículas foram colhidas individualmente e a porcentagem de cariopses infetadas foi determinada através de plaqueamento em meio de cultura. As cariopses em formação, expostas ao inóculo durante os estágios de grão leitoso e massa mole, apresentaram as maiores incidências do patógeno. A temperatura e o nível de precipitação não influenciaram a porcentagem de cariopses infetadas pelo patógeno, no entanto, temperaturas altas, precipitação elevada e a ocorrência de outras moléstias, anteciparam a senescência das folhas basais, favorecendo a produção de inóculo pelo patógeno.

Palavras-chave adicionais: Avena sativa, epidemiologia, helmintosporiose.

\section{ABSTRACT}

Establishment of Pyricularia chaetomioides in white barley caryopsis under field conditions

Oat (Avena sativa) is one of the most important crops in South Brazil. As acreage increases, particularly in the no-till system, some diseases became more significant. In order to identify which growth stage of the kernel is more susceptible to the establishment of the fungus Pyrenophora chaetomioides, three experiments were conducted under field conditions. Oat panicles were exposed to natural inoculum during specific periods of time from their extrusion. To

protect the panicles from the inoculum, cellophane bags were used to cover them. At the end of the cycle the panicles were individually harvested and the percentage of infected kernels was calculated after plating them in an artificial medium. The kernels exposed to the inoculum during the milk and dough stages showed the highest percentages of infection. Temperature and precipitation did not contribute to the infection, although high temperature and precipitation along with occurrence of other diseases anticipated the senescence of basal leaves, favoring the inoculum production.
\end{abstract}

O aumento da área de cultivo de aveia branca (Avena sativa $\mathrm{L}$.) no Brasil, principalmente em plantio direto, tem ocasionado o aumento na intensidade da mancha foliar e do grão causada por Pyrenophora chaetomioides Speg. A ocorrência de grãos manchados deprecia o produto e impede sua comercialização, resultando na perda total dos lotes que apresentam alta porcentagem de grãos escurecidos.

Durante o desenvolvimento das cariopses, no estágio de grão aquoso, o comprimento e a largura da cariopse são estabelecidos. Há um rápido aumento em tamanho, mas com pouca acumulação de matéria seca. Horigane et al. (2001) relatam que na fase aquosa ocorre o início dos processos biológicos, como reações enzimáticas, transporte e acumulação de materiais. Durante o estágio leitoso, os nutrientes estocados nas folhas inferiores são redistribuídos para a parte superior da planta, inclusive para as cariopses em formação. Nesta fase inicia a morte da folhas basais da planta. Quando atinge o estado de massa mole, a cariopse rapidamente acumula reservas de nutrientes e sua coloração começa a passar do verde para o amarelo. Muito da matéria seca é acumulada nesse estágio. No final do estágio de massa dura, ocorre a maturação fisiológica e a concentração de água decresce para 30 a $40 \%$. No estágio de grão duro, a planta está completamente amarela e o teor de água na cariopse fica entre 20 e $25 \%$. No final do ciclo, a planta seca completamente e as cariopses atingem a maturação de colheita com 13 a $14 \%$ de umidade.

A fase secundária da doença, a qual ocorre nas folhas mais velhas e nas cariopses, está associada com períodos de lento crescimento, caracterizado pela alta porcentagem relativa de carbohidratos no hospedeiro (Coffman, 1961). A fase secundária leva à infecção das cariopses, o que pode ocorrer no intervalo de três a 21 dias, dependendo do estágio de desenvolvimento, das condições de umidade, temperatura e da densidade do inóculo (Schilder \& Bergstrom, 1994). Mesmo que a infecção foliar secundária seja severa, a colheita em condições secas reduz a contaminação das sementes 
(Shaner, 1981).

Nesse contexto, os objetivos deste trabalho foram identificar em qual estágio de desenvolvimento as cariopses de aveia branca apresentam maior suscetibilidade à infecção por $P$. chaetomioides e qual a importância da temperatura e da precipitação nesse processo, na região sul do Brasil.

Os experimentos foram instalados em solo Podzólico Vermelho Escuro manejado no sistema plantio-direto, na Estação Experimental Agronômica (EEA) da UFRGS, no município de Eldorado do Sul, em 2000 e 2001. Na área experimental utilizada não havia sido cultivada aveia branca no inverno anterior, garantindo a inexistência de inóculo do patógeno na área. Na safra 2000, utilizaram-se as cultivares UFRGS 15, UFRGS 16 e UFRGS 19, semeadas em 13/junho, 23/ junho e $07 /$ julho. O delineamento experimental utilizado foi parcela sub-subdividida com oito repetições, tendo na parcela principal a data de semeadura, na sub-parcela a cultivar e na sub-subparcela o tratamento. Em 2001 foi utilizada a cultivar UFRGS 19, com semeadura em 11/junho no delineamento inteiramente casualizado com oito repetições. A unidade experimental nos dois anos foi formada por três panículas escolhidas ao acaso.

Os tratamentos aplicados nas panículas das plantas de aveia consistiram na proteção (T1), na exposição (T2) ou na combinação dos dois tratamentos (T12), através da utilização de sacos com $10 \mathrm{~cm}$ de largura e $25 \mathrm{~cm}$ de comprimento, confeccionados com papel celofane incolor e cola branca à base de acetato de polivinil. O tratamento T1 foi aplicado através da colocação semanal dos sacos em três panículas de plantas das cultivares UFRGS 15, UFRGS 16 e UFRGS 19, durante a formação das cariopses. Com isso, as panículas foram sendo ensacadas de modo a permaneceram protegidas por períodos decrescentes de tempo até o final do ciclo. Para a aplicação do tratamento T2, 50 panículas de plantas das cultivares UFRGS 15, UFRGS 16 e UFRGS 19 foram ensacadas individualmente quando se encontravam no estágio 47 (final do emborrachamento) na escala de desenvolvimento de Zadoks (EDZ) (Zadoks et al., 1974). Posteriormente, os sacos foram sendo retirados semanalmente das panículas, permitindo sua exposição ao inóculo por períodos de tempo decrescentes até o final do ciclo. Para a execução do tratamento T12, em 2001, 30 panículas de plantas da cultivar UFRGS 19 foram ensacadas em EDZ 47 (final do emborrachamento). Semanalmente, os sacos foram sendo retirados das panículas e, após o intervalo de aproximadamente sete dias, re-colocados. A aplicação desse tratamento permitiu que durante o período de formação das cariopses houvessem panículas expostas ao inóculo em intervalos semanais pré-determinados. Em cada repetição, três colmos foram submetidos individualmente aos tratamentos, utilizando barbante de cores diferentes para a fixação dos sacos e identificação da semana de aplicação do respectivo tratamento. Foram adotadas como padrão uma testemunha positiva (TESTEMUNHA 1), cujas panículas permaneceram ensacadas durante todo o período experimental e uma testemunha negativa (TESTEMUNHA 2), formada por panículas que não receberam tratamento.
Na safra 2001, foi conduzido um segundo experimento onde a proteção das panículas ao longo do período de desenvolvimento das cariopses foi realizada através da aplicação de fungicida nas mesmas épocas em que foram aplicados os tratamentos T1, T2 e T12. Foi utilizado o fungicida Tebuconazole ( $150 \mathrm{~g} / \mathrm{ha}$ de ingrediente ativo), pulverizado sobre a parte aérea de plantas de aveia branca da cultivar UFRGS 19, semeadas em parcelas de $5 \mathrm{~m}^{2}$ no delineamento experimental inteiramente casualizado, com oito repetições.

No final do ciclo, as panículas foram colhidas e trilhadas manualmente. Após desinfestação superficial com álcool $70 \%$ por 1,5 min e hipoclorito de sódio $1 \%$ por 3,5 min, seguida de três lavagens suscessívas em água destilada esterilizada, as cariopses foram colocadas em placas de Petri contendo aproximadamente $15 \mathrm{ml}$ de meio de cultura BDA modificado (100 g de batata; $5 \mathrm{~g}$ de açúcar; $12 \mathrm{~g}$ de ágar; $0,10 \mathrm{~g}$ de sulfato de streptomicina; $1.000 \mathrm{ml}$ de água destilada). Cada placa de Petri, após receber dez cariopses, foi vedada com filme plástico e identificada com a respectiva data de aplicação do tratamento. A incubação das placas foi realizada em câmara de crescimento a $23{ }^{\circ} \mathrm{C}$ durante cinco dias. Embora as Regras para Análise de Sementes (Brasil/Ministério da Agricultura e do Abastecimento, 1992) recomendem que sejam utilizadas 400 sementes nas análises, devido a limitações experimentais e a pouca variação em relação ao número recomendado, foram avaliadas 30 cariopses para cada repetição, totalizando 240 cariopses por tratamento. Ensaios preliminares mostraram que o plaqueamento de um menor número de cariopses com elevada incidência de $P$. chaetomioides apresenta relação direta com os resultados obtidos na análise de 400 sementes. A avaliação consistiu na observação das placas de Petri em microscópio estereoscópico Leica (modelo MZ12), onde foi realizada a identificação e contagem direta das colônias de $P$. chaetomioides. Os dados obtidos foram submetidos à análise de variância (teste F) e as médias dos tratamentos foram comparadas pelo teste de Tukey ao nível de $5 \%$ de significância.

Houve interação significativa entre datas de semeadura e cultivares na incidência de $P$. chaetomioides nas cariopses. Na comparação entre médias, a cultivar UFRGS 19 apresentou a menor incidência, diferindo das cultivares UFRGS 15 e UFRGS 16 , que, por sua vez, não mostraram diferença significativa entre si em duas épocas de semeadura (Tabela 1).

A menor incidência de $P$. chaetomioides nas cariopses da cultivar UFRGS 19 em comparação com UFRGS 15 e UFRGS 16 , sugere, em primeira análise, a existência de algum mecanismo de resistência naquela cultivar. Isto, segundo Schilder \& Bergstrom (1994), pode ser explicado pela incompatibilidade das cariopses à infecção, por diferenças no microambiente das espiguetas ou pela restrição da invasão do fungo nas cariopses e tecidos florais. No entanto, a variação nos níveis de incidência do patógeno, observada entre épocas de semeadura, indica que a evasão talvez tenha sido o mecanismo envolvido. Como UFRGS 19 é uma cultivar de ciclo semi-precoce, a fuga em relação ao patógeno e as condições ambientais mais favoráveis ao seu desenvolvimento, pode estar causando a menor 
TABELA 1 - Incidência (\%) de Pyrenophora chaetomioides em cariopses de aveia branca (Avena sativa) das cultivares UFRGS 15, UFRGS 16 e UFRGS 19, colhidas em Eldorado do Sul, no ano de 2000

\begin{tabular}{|c|c|c|c|c|}
\hline \multirow{2}{*}{ Cultivar } & \multicolumn{3}{|c|}{ Datas de semeadura } & \multirow{2}{*}{$\begin{array}{l}\text { Média das } \\
\text { cultivares }\end{array}$} \\
\hline & 13/junho & $23 /$ junho & 07/julho & \\
\hline Ufrgs 16 & $21,8 \mathrm{a} \mathrm{A}^{*}$ & 14,2 a B & 15,2 a B & $16,9 \quad \mathrm{a}$ \\
\hline Ufrgs 15 & 13,8 b A & 11,2 a A & 14,2 a A & $13,0 \quad \mathrm{a}$ \\
\hline Ufrgs 19 & 4,5 c B & 10,0 a A & 4,1 b B & $6,0 \mathrm{~b}$ \\
\hline
\end{tabular}

*médias seguidas de mesma letra, minúscula na vertical e maiúscula na horizontal, não diferem entre sí pelo teste de Tukey a $5 \%$.

incidência do patógeno nas cariopses dessa cultivar. Segundo Agrios (1988), as condições ambientais afetam o desenvolvimento das doenças através da sua influência no crescimento e desenvolvimento do hospedeiro e na multiplicação e atividade do patógeno. Mudanças em qualquer fator ambiental podem favorecer o hospedeiro, o patógeno, ou ambos, ou ser mais favorável para um do que para outro. Desse modo, a variabilidade de resposta das cultivares à infecção pode ter sido devida a diferenças nas condições ambientais entre épocas de semeadura.

Em 2000, no tratamento T1, as panículas que foram protegidas nas primeiras três semanas apresentaram níveis de incidência de $P$. chaetomioides nas cariopses menores do que aquelas protegidas da quarta semana em diante. No tratamento T2, as panículas que foram expostas ao inóculo a partir da primeira, segunda ou terceira semanas tiveram maiores incidências do que aquelas que foram expostas somente a partir da quarta semana (Tabela 2). Na safra 2001, as panículas do tratamento $\mathrm{T} 1$, que foram protegidas nas primeiras quatro semanas, apresentaram menores níveis de incidência do que aquelas que foram protegidas a partir da quinta, sexta, sétima ou oitava semanas. Já as panículas do tratamento T2, expostas ao inóculo a partir da primeira até a sexta semana após sua emergência, apresentaram maiores valores de incidência de $P$. chaetomioides do que aquelas expostas a partir da sétima ou oitava semanas. Do mesmo modo, os resultados do tratamento T12 mostraram que a maior incidência do patógeno nas cariopses ocorreu quando as panículas ficaram expostas apenas na quarta, na quinta ou na sexta semanas após a emergência (Tabela 3).

Nos dois anos de condução do experimento, os níveis de incidência de $P$. chaetomioides nas panículas submetidas aos tratamentos T1, T2 e T12, foram maiores quando as cariopses estavam em EDZ 75 e 85 (grão leitoso e grão em massa mole, respectivamente). Nesses estágios há o início da re-distribuição dos nutrientes acumulados pela planta durante a fase vegetativa para as cariopses em formação. Além disso, a presença de água na rede vascular do pericarpo como um prérequisito para a atividade biológica nesse tecido, cria condições ótimas para o desenvolvimento do fungo (Horigane et al., 2001). A maior disponibilidade de nutrientes nas sementes, juntamente com condições ambientais favoráveis, podem ter determinado o sucesso do patógeno na colonização das
TABELA 2 - Incidência (\%) de Pyrenophora chaetomioides em cariopses de aveia (Avena sativa) branca colhidas a partir de panículas submetidas aos tratamentos de proteção (T1) e exposição (T2) em Eldorado do Sul, no ano de 2000

\begin{tabular}{|c|c|c|}
\hline \multirow{2}{*}{ Data do tratamento } & \multicolumn{2}{|c|}{ Condição das panículas } \\
\hline & Protegidas (T1) $^{1}$ & Expostas (T2) \\
\hline 06/outubro & $4,5 \mathrm{~cd}$ & $20,2 \mathrm{a}^{*}$ \\
\hline 14/outubro & $5,5 \mathrm{c}$ & 21,8 a \\
\hline 20/outubro & 8,4 bc & 20,9 a \\
\hline 28/outubro & $14,1 \quad b$ & $7,3 \mathrm{~b}$ \\
\hline Testemunha $1^{3}$ & $1,7 \mathrm{~d}$ & $3,1 \quad b$ \\
\hline Testemunha $2^{4}$ & 28,2 a & 28,2 a \\
\hline
\end{tabular}

*médias seguidas de mesma letra na coluna não diferem entre si pelo teste de Tukey a $5 \%$.

${ }^{1}$ panículas protegidas por períodos decrescentes de tempo até o final do ciclo; ${ }^{2}$ panículas expostas por períodos decrescentes de tempo até o final do ciclo; ${ }^{3}$ panículas protegidas durante todo o período experimental; ${ }^{4}$ panículas que não receberam tratamento.

TABELA 3 - Incidência (\%) de Pyrenophora chaetomioides em cariopses de aveia branca (Avena sativa) colhidas a partir de panículas submetidas aos tratamentos de proteção (T1) e exposição (T2) em Eldorado do Sul, no ano de 2001

\begin{tabular}{|c|c|c|c|c|c|c|}
\hline \multirow{3}{*}{$\begin{array}{l}\text { Data do tratamento } \\
27 \text { /agosto }\end{array}$} & \multicolumn{6}{|c|}{ Condição das panículas } \\
\hline & \multicolumn{2}{|c|}{$\begin{array}{c}\text { Protegidas } \\
\text { (T1) }\end{array}$} & \multicolumn{2}{|c|}{$\begin{array}{c}\text { Expostas } \\
(\mathrm{T} 2)^{2}\end{array}$} & \multicolumn{2}{|c|}{$\begin{array}{c}\text { Expostas } \\
(\mathrm{T} 12)^{5}\end{array}$} \\
\hline & 2,7 & $c^{*}$ & 12,5 & cde & 2,5 & $\mathrm{c}$ \\
\hline 03/setembro & 1,7 & $\mathrm{c}$ & 14,6 & $\mathrm{~cd}$ & 2,3 & $\mathrm{c}$ \\
\hline $10 /$ setembro & 2,5 & $\mathrm{c}$ & 20,1 & $\mathrm{bc}$ & 6,8 & bc \\
\hline $17 /$ setembro & 4,7 & bc & 36,5 & $a b$ & 18,8 & a \\
\hline $24 /$ setembro & 15,1 & $\mathrm{a}$ & 26,0 & $\mathrm{abc}$ & 20,1 & a \\
\hline 01/outubro & 16,8 & a & 37,3 & a & 18,2 & $\mathrm{ab}$ \\
\hline 08/outubro & 8,6 & $a b c$ & 5,2 & def & 6,6 & bc \\
\hline 15/outubro & 16,6 & a & 3,9 & ef & - & - \\
\hline Testemunha $1^{3}$ & 2,0 & $\mathrm{c}$ & 2,0 & $\mathrm{f}$ & 2,0 & $\mathrm{c}$ \\
\hline Testemunha $2^{4}$ & 17,3 & $\mathrm{a}$ & 17,3 & $\mathrm{c}$ & 17,3 & $\mathrm{ab}$ \\
\hline
\end{tabular}

*médias seguidas de mesma letra na coluna não diferem entre si pelo teste de Tukey a $5 \%$.

${ }^{1}$ panículas protegidas por períodos decrescentes de tempo até o final do ciclo; ${ }^{2}$ panículas expostas por períodos decrescentes de tempo até o final do ciclo; ${ }^{3}$ panículas protegidas durante todo o período experimental; ${ }^{4}$ panículas que não receberam tratamento; ${ }^{5}$ cariopse expostas ao inóculo de ambiente por um período de uma semana durante a fase de formação dos grãos.

cariopses durante esse período.

A aplicação do fungicida Tebuconazole reduziu a incidência de $P$. chaetomioides nas cariopses. A maior redução na incidência em relação à testemunha ocorreu quando o produto foi aplicado em EDZ 85 (grão em massa mole), em torno da quarta semana após a emergência das panículas (Figura 1), quando o inóculo e as condições ambientais eram favoráveis ao patógeno. Nesse sentido, Bailey \& Duczek (1996), afirmam que o uso de fungicidas no sistema plantiodireto se justifica quando a pressão de inóculo durante a estação de cultivo é alta e as condições ambientais favoráveis à ocorrência de epidemias.

Os resultados sugerem que durante a formação das 
cariopses de aveia branca, entre EDZ 75 (grão leitoso) e EDZ 85 (grão em massa mole), ocorre o período de maior suscetibilidade à infecção por $P$. chaetomioides.

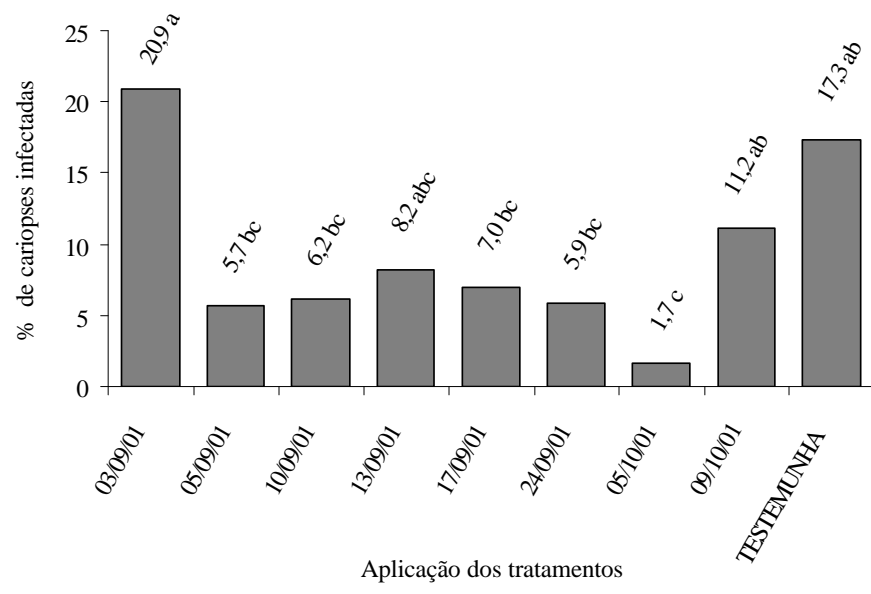

FIG. 1 - Incidência de Pyrenophora chaetomioides em cariopses de aveia branca (Avena sativa) tratadas com o fungicida Tebuconazole em diferentes datas durante a formação do grão em Eldorado do Sul, em 2001.

\section{REFERÊNCIAS BIBLIOGRÁFICAS}

AGRIOS, G.N. Plant Pathology. New York. Academic Press. 1988.

BAILEY, K.L. \& DUCZEK, L.J. Managing cereal diseases under reduced tillage. Canadian Journal of Plant Pathology 18:159-167. 1996.

BRASIL. Ministério da Agricultura e do Abastecimento. Regras para análise de sementes. Brasília, 1992.

COFFMAN, F.A. Oats and Oat improvement. Madison. The American Society of Agronomy, 1961.

HORIGANE, A.K., ENGELAAR, W.M.H.G., MARUYAMA, S., YOSHIDA, M., OKUBO, A. \& NAGATA, T. Visualization of moisture distribution during development of rice caryopses (Oryza sativa L.) by nuclear magnetic resonance microimaging. Journal of Cereal Science 33:105-114. 2001.

SCHILDER, A.M. \& BERGSTROM, G.C. Infection of wheat seed by Pyrenophora tritici-repentis. Canadian Journal of Botany 72:510519. 1994.

SHANER, G. Effect of environment on fungal leaf blights of small grains. Annual Review of Phytopathology 19:273-269. 1981.

ZADOKS, J.C., CHANG, T.T. \& KONZAK, C.F. A decimal code for the growth stages of cereals. Weed Research 14:415-421. 1974. 